\title{
КОЛИЧЕСТВЕННАЯ ОЦЕНКА ПРИЖОГОВ ПРИ ПЛОСКОМ ШЛЛИФОВАНИИ ЗАКАЛЕННЫХ ДЕТАЛЕЙ ИЗ СТАЛИ ЧОХ АБРАЗИВНЫМИ КРУГАМИ РАЗЛИЧНОЙ ПОРИСТОСТИ
}

\author{
Я.И. СОЛЕР, канд. техн. наук, доцент \\ Д.Ю. КАЗИМИРОВ, канд. техн. наук, доцент \\ В.Л. НГУЕН, аспирант \\ (ИрГТУ, г. Иркутск)
}

Поступила 20 января 2015

Рецензирование 10 февраля 2015

Принята к печати 15 февраля 2015

\begin{abstract}
Солер Я.И. - 664074, г. Иркутск, ул. Лермонтова, 83, Иркутский государственный технический университет, e-mail: solera@istu.irk.ru
\end{abstract}

Разработана методика количественной оценки прижогов на базе цифровых технологий. Она апробирована в условиях маятникового шлифования закаленных деталей из стали $40 \mathrm{X}$ абразивными инструментами различной пористости: 25AF46L10V5КФ35 $(i=1), 25 \mathrm{AF} 46 \mathrm{M} 12 \mathrm{~V} 5 \Pi \mathrm{O} 3(i=2)$, EKE46K3V $(i=3)$, 5A46L10VAX $(i=4)$. Инструменты $i=1 ; 2$ относятся к высокопористым кругам (ВПК), а круги $i=3 ; 4$ из монокристаллического корунда имеют стандартную пористость (изготовитель - фирма Dorfner schleifmittelwerk (Германия)).

Для подтверждения надежности предложенной методики оценки прижогов параллельно проведено исследование микротвердости деталей. Учитывая стохастическую природу шлифования, для обработки наблюдений привлечены статистические методы: параметрический и непараметрический (в частности, ранговый). Их достоинствами является возможность оценки надежности принимаемых решений, а также режущих способностей кругов не только по мерам положения, но и рассеяния. Вторая характеристика одномерного распределения частот наиболее важна при шлифовании ответственных деталей на настроенных станках с ручным управлением с целью снижения вероятности брака. Показано, что в условиях нарушений гомоскедастичности и нормальности распределений наблюдений параметрический метод «на чужом поле» привел к смещению мер положения и доверительных интервалов. Установлена корреляционная связь между мерами положения для плотности прижогов и микротвердости при шлифовании абразивными инструментами на режиме $\mathrm{v}_{\mathrm{\kappa}}=35 \mathrm{~m} / \mathrm{c}, s_{\text {пр }}=7 \mathrm{~m} /$ мин, $s_{\text {п }}=1 \mathrm{мм} /$ дв. ход, $t=0,015 \mathrm{мм}, z=0,15$ мм, который обеспечивает наибольшую микротвердость деталей $40 \mathrm{X}$ при минимальных прижогах. Проведенное исследование показало, что шлифование деталей исследуемыми кругами протекает в условиях разупрочнения их поверхностей, но без вторичной закалки.

Ключевые слова: шлифование, прижоги, микротвердость, статистика, среднее, медиана, мера рассеяния, цифровые технологии.

DOI: $10.17212 / 1994-6309-2015-1-6-19$

\section{Введение}

В процессе абразивного шлифования деталей из закаленных сталей существует большая вероятность повреждения их поверхности вследствие возникновения прижогов, которые являются одним из наиболее распространенных и сложных дефектов при работе «жесткими» абразивными инструментами. Это связано с превращением работы резания в теплоту. Их источником служат абразивные зерна, которые с учетом расположения в радиальном направлении разделяются на три группы: режущие, давящие и нережущие. Наиболее выступающие абразив- 
ные зерна первоначально производят упругую деформацию металла, затем пластическую, и по достижении контактных напряжений, превышающих предел прочности металла, - снятие стружки. Тепло образуется в основном в результате трения абразивных зерен по ювенильной поверхности только что обработанного металла и энергии, расходуемой на упругую и пластическую деформацию. При этом на первых двух этапах контакта режущих зерен с металлом температура шлифуемой поверхности оказывается даже выше, чем при снятии стружки. Давящие зерна лишь скользят по ранее обработанной поверхности, вызывая дополнительно упругую и пластическую деформацию и тепловыделение. Мгновенный нагрев поверхности заготовки может составлять $700 \ldots 800{ }^{\circ} \mathrm{C}$ и приводит ее к локальному оплавлению. При этом скорость нагрева достигает 5000..6000 ${ }^{\circ} \mathrm{C} / \mathrm{c}$ и даже до 10000 C/c. Тепловое поле заготовки характеризуется высоким градиентом и сосредоточивается в поверхностном слое глубиной до $0,1 \ldots 0,3$ мм. Практически за доли секунды эта температура снижается, так как основная часть тепла отводится в нижележащие слои холодного металла. При интенсивном съеме металла температуры нагрева могут быть выше фазового превращения (линии $A_{c 1}$ ). Нагретый металл, взаимодействуя с охлаждающей средой, приобретает пониженную или повышенную твердость поверхностного слоя детали. При этом в сталях с мартенситной и сорбитной структурой возможна вторичная закалка $[1,2]$.

В работах [3-5] прижоги классифированы на две группы: закалки и отпуска. В первом случае в результате нагрева металла выше линии $A_{c 1}$ образующийся при шлифовании аустенит при остывании деталей не достигает полного обратного мартенситного превращения. Это связано с тем, что в результате больших удельных давлений, оказываемых абразивными зернами на их поверхности, и скорости движения теплового источника нижняя граница мартенситного превращения смещается ниже $20{ }^{\circ} \mathrm{C}$. В результате на поверхности детали фиксируется структура аустенита закалки, который может иметь две схемы превращений: диффузионную «мартенсит - перлит - аустенит» и бездиффузионную «мартенсит - аустенит». В первом случае протекает выход углерода из кристаллической ре- шетки мартенсита в зоне температуры отпуска, а при дальнейшем повышении нагрева $\alpha \rightarrow \gamma$ превращение и растворение углерода в $\gamma-\mathrm{Fe}$, т. е. образование аустенита. Бездиффузионная схема обратного мартенситного превращения предполагает только сдвиг кристаллической решетки при минимальном времени воздействия теплового источника $\left(10^{-11} \mathrm{c}\right)$. Прижоги второй группы протекают в третьем превращении отпуска, когда углерод полностью выходит из решетки мартенсита. При этом образуется феррит, а в результате реакции между ним и выделившимся углеродом - цементит (перлит).

Снижение твердости, обусловленное прижогами, оказывает неблагоприятное воздействие на усталостную прочность, износостойкость и, как следствие, долговечность деталей машин [6]. В связи с этим при шлифовании высоконагруженных и ответственных деталей контролю прижогов уделяется большое внимание. Существующие методы контроля разделяются на разрушающие и неразрушающие. Одним из самых известных разрушающих методов контроля является химическое травление, при котором химические растворы реагируют с отдельными структурными составляющими, находящимися на поверхности детали [7, 8]. Дополнительно прижоги контролируются внешним осмотром. Однако метод травления дает информацию лишь о грубых структурных изменениях в поверхностном слое деталей, характеризуется высокой трудоемкостью и экологически опасен. Поэтому ведется непрерывный поиск более современных, неразрушающих способов контроля прижогов. В работе [7] предложен метод, основанный на измерении удельного сопротивления металла, которое возрастает при возникновении прижогов вторичной закалки и уменьшается при прижогах вторичного отпуска. Позднее создан способ выявления прижогов, описанный в работе [9], по электризации и свечению их зон в ультрафиолетовом свете после нанесения специального вещества на поверхность. В работе [10] авторами предложен способ выявления зон со шлифовочными и эксплуатационными прижогами путем измерения на поверхности деталей флуктуации физического параметра, в качестве которого принята работа выхода электронов. Для цементируемых и улучшаемых легированных сталей с мартенситной структурой часто 
используют рентгеновский метод [3, 11], который позволяет оценить степень прижогов по количеству остаточного аустенита в шлифованном слое деталей. В научных целях используют металлографический метод, который связан с изготовлением шлифов, их травлением и изучением структур на металлографическом микроскопе. Он обладает высокой точностью, но его отличает высокая трудоемкость и возможность только выборочного контроля в лабораторных условиях [11]. В последнее время за рубежом получил распространение метод обнаружения прижогов с использованием эффекта Баркгаузена по анализу шумов $[12,13]$. При этом повышение сигнала шумов Баркгаузена свидетельствует о снижении твердости и росте остаточных напряжений растяжения в результате прижогов вторичного отпуска. В противном случае их снижение свидетельствует о прижогах, обусловленных вторичной закалкой.

Большинство из рассмотренных методов контроля обладают высокой трудоемкостью, трудно автоматизируются и не всегда дают количественную оценку прижогов. В работе [14] предложено использовать планшетный сканер и анализ фотографий по плотности оттенков серого тона, которые не позволяют выявить различную интенсивность прижогов.

Задачей данной работы является разработка методики количественной оценки прижогов на основе цифровых технологий. Это позволит повысить качество изготовления ответственных деталей, в частности, путем выбора абразивных кругов по минимальному тепловому воздействию на поверхность.

\section{Методика проведения эксперимента}

Натурные опыты выполнены при следующих неизменных условиях: оборудование - плоскошлифовальный станок модели $3 Г 71$; детали из стали 40Х ( $\left.\sigma_{\text {в }}=980 \mathrm{MПа}, \delta=10 \%\right)$ перед шлифованием прошли термообработку: закалку $860{ }^{\circ} \mathrm{C}$ в масле, отпуск $500{ }^{\circ} \mathrm{C}$, вода или масло [15]; размеры шлифуемой поверхности $L \times B=$ $=30 \times 40$ мм; число повторений опытов $n=10-$ при оценке прижогов, $n=30$ - при измерении микротвердости; СОЖ - 5 \%-я эмульсия Аквол - 6 (ТУ 0258-024-00148845-98), подаваемая поливом на деталь с расходом 7...10 л/мин; правка круга - алмазным карандашом перед шлифованием каждой детали; режим обработки - скорость резания $\mathrm{v}_{\mathrm{\kappa}}=35 \mathrm{M} / \mathrm{c}$, продольная подача $s_{\text {пр }}=7 \mathrm{M} / \mathrm{мин,}$ поперечная подача $s_{\text {п }}=1 \mathrm{mм/дв.} \mathrm{ход,} \mathrm{глубина}$ резания $t=0,015$ мм, операционный припуск $z=0,15$ мм. Шлифование ведут абразивными кругами формы 1 с размерами $250 \times 20 \times 76$ мм. Их характеристики представлены кодом $i=\overline{1,4}$, который удобен при статистической обработке наблюдений: 1 - 25AF46L10V5КФ35 (абразивный завод «Ильич», г. Санкт-Петербург); 2 - 25AF46M12V5ПО3 (Лужский абразивный завод, г. Луга); 3 - EKE46K3V; 4 - 5A46L10VAX. Круги $i=\overline{3,4}$ изготовлены фирмой Dorfner schleifmittelwerk (Германия) и содержат зерна монокорунда, маркировка которых зависит от метода получения и отличается от российской: EKE - для литых, 5А - для прессованных. Обозначение других элементов характеристики у круга $i=4$ в наибольшей мере совпадает с российской, за исключением номеров структур. Российские круги $i=\overline{1,2}$ со структурами 10-12 относятся к высокопористым (ВПК), а у круга $i=4$ - к открытой, поскольку фирма Dorfner schleifmittelwerk к ВПК относит номера структур 13-20. В литом инструменте $i=3$ индекс К указывает на среднюю структуру, а цифра 3 - на его твердость «мягкая».

После шлифования поверхность изделия очищали от пыли и загрязнений. Фотографирование вели в двух взаимно ортогональных направлениях, совпадающих с векторами $s_{\text {п }}$ и $s_{\text {пр }}$. Съемка велась под искусственным светом от набора студийных осветителей Smartum с источниками 5500 К через рассеиватели, что позволило устранить возможные полутени. Режим макросъемки: фокусное расстояние 250 мм со штатива цифровой зеркальной фотокамерой Nikon D3100 с матрицей CMOS, с общим количеством пикселей 14,2 млн, с объективом Nikon 18 ...55 мм f/3,5-5,6G AF-S VR DX Zoom-Nikkor, с чувствительностью ISO400 и максимальным разрешением снимка $4608 \times 3072$. Макросъемка позволила каждую элементарную площадку поверхности отразить пикселем соответствующего цвета. При этом участки поверхности с прижогами имеют более темные цвета. Они отличаются от цветов металла без прижогов, которые на реальной поверхности выражены недостаточно контрастно. Сказанное затрудняет конвертиро- 
вание программы. В связи с изложенным исходный фотоснимок, сохраняющийся в виде фотофайла с расширением JPEG, преобразовывался программой Adobe Photoshop CS6 13.1.2, имеющей специальный инструмент «Shadow/ Highlight - тени/света», который позволил преобразовать темные участки (прижоги) и светлые участки (без прижогов) в различные цвета. Это облегчает конвертирование растровых изображений цветов, закодированных в $H T M L-$ и $R G B$ кодах, которые сохраняются в виде $t x t$ файла с возможными оттенками цветов не более $j=16$ [16]. В файле прижоги представлены несколькими кодами $j=\overline{1 ; 3}: 1-R G B-(128,128,0) ; 2-$ $(0,128,0) ; 3-(128,0,0)$, которые соответствуют HTML: \#808000 olive, \#008000 green, \#800000 maroon. Количество прижогов для одной из деталей $v=\overline{1 ; 10}$, прошлифованной кругом $i$, рассчитывается из выражения

$$
\Pi_{i v}=\left(\frac{\sum P_{j п \mathrm{p}}}{\sum P_{j}}\right)_{i v} 100 \%, i=\overline{1 ; 4},
$$

где $\Pi_{i v}-$ плотность прижогов поверхности $v$-й детали в процентах; $\Sigma P_{i j}, j=\overline{1 ; 3}$ - общее количество пикселей цветов прижогов; $\Sigma P_{i j}-$ общее количество всех пикселей при переменном $j$ при тех же условиях шлифования.

Дополнительно на приборе ПМТ-3 проведено измерение микротвердости шлифованных поверхностей деталей $H V_{i}$ по методике [17], которое позволяет оценить адекватность предлагаемой методики количественного содержания прижогов.

Для анализа экспериментальных данных в работе используются статистические подходы, обусловленные стохастической природой процесса шлифования. Получаемые параметры прижогов поверхности (1) и микротвердости представляют собой случайные величины (CB), образующие независимые множества:

$$
\left\{y_{i v}\right\}, \quad i=\overline{1 ; 4}, \quad v=\overline{1 ; n} .
$$

Существует два направления статистических методов: параметрическое и непараметрическое (в частности, ранговое), используемых для изучения СВ. Характеристиками одномерного распределения частот для (2) служат [18-20]: средние $\overline{y_{i}}=y_{i \bullet}$, стандарты отклонений $(S D)_{i}$, размахи $R_{i}=\left|y_{\max }-y_{\min }\right|_{i}-$ для первого направления; медианы $\tilde{y}_{i}$, квартильные широты $\mathrm{KШ}_{i}=\left|y_{0,75}-y_{0,25}\right|_{i}-$ для второго направления. Первая из указанных частот характеризует меру положения (опорное значение) $\mathrm{CB}$, а последующие - меры рассеяния (прецизионность). Сдвиг $y_{i} \bullet$ и $\tilde{y}_{i}$ свидетельствует об асимметрии (скошенности) кривой распределений, которая приближенно вычисляется из выражения [18]:

$$
A s_{i}=\left[3\left(y_{\bullet}-\tilde{y}\right) / S D\right]_{i}, i=\overline{1 ; 4} .
$$

Параметрический метод статистики используется в том случае, когда (2) обладают свойствами гомоскедастичности (синонимы - однородность или гомогенность дисперсий отклонений) и нормальности распределений. При нарушении этих ограничений рекомендуется, в частности, привлекать ранговый метод, который не связан с конкретным семейством распределений и его свойствами. В работе [18] изложены методика выбора статистического метода и последующий поиск ожидаемых средних $\hat{y}_{i}$ и медиан $m \hat{y}_{i}, i=\overline{1 ; 4}$. На первом этапе для (2) проводится одномерный дисперсионный анализ (ОДА) на предмет установления факта значимого различия между уровнями мер положения, а на последующем - их множественный анализ, который завершается поиском ожидаемых аналогов для переменной $i=\overline{1 ; 4}$. Обработка наблюдений (2) требует большого объема вычислений и проведена в программной среде Statistica 6.1.478.0.

Влияние непараметрического метода на меры положения оценивается медианными коэффициентами при неизменном $i=\overline{1 ; 4}$ :

$$
\begin{gathered}
\mathrm{K}_{\mathrm{M} i}=\left(\tilde{y} / y_{\bullet}\right)_{i}, \\
\widehat{\mathrm{K}}_{\mathrm{M} i}=\left(m \hat{y} / \hat{y}_{\bullet}\right)_{i} .
\end{gathered}
$$

Оценку работоспособности кругов $i=\overline{2 ; 4}$ относительно базового ВПК 25AF46L10V5КФ35 $(i=1)$ ведем для обеих характеристик одномерного распределения частот (2) [21, 22]:

$$
\begin{gathered}
\mathrm{K}_{i}=\tilde{y}_{i} / \tilde{y}_{1}, \\
\widehat{\mathrm{K}}_{i}=m \hat{y}_{i} / m \hat{y}_{1},
\end{gathered}
$$




$$
\begin{gathered}
\mathrm{K}_{\text {ст } i 1}=S D_{1} / S D_{i}, \\
\mathrm{~K}_{\text {ст } i 2}=R_{1} / R_{i}, \\
\mathrm{~K}_{\text {ст } i 3}=\mathrm{KW}_{1} / \mathrm{KW}_{i},
\end{gathered}
$$

где индексы $e=\overline{1 ; 3}$ в (7)-(9) отражают принятые меры рассеяния: 1 - по $S D_{i} ; 2$ - по $R_{i}$; 3 - по КШ. Если предсказаны: $\left(\mathrm{K}_{i}, \widehat{\mathrm{K}}_{i}\right)>1$ и $\mathrm{K}_{\text {стіе }}<1, e=\overline{1 ; 3}$, то меры положения и рассеяния выходных параметров процесса при шлифовании кругами $i=\overline{2 ; 4}$ превышают аналоги для базового ВПК 25AF46L10V5КФ35 $(i=1)$ и уступают ему по выбранным критериям стабильности процесса; в противном случае превосходят их.

Коэффициенты (4), (6)-(9) необходимы для комплексной оценки режущих способностей абразивных кругов и расширения информационной базы при многокритериальном управлении процессом шлифования с использованием моделей многомерного дисперсионного анализа с учетом конструктивных особенностей и служебного назначения деталей [23]. Опытный медианный коэффициент (3) позволяет оценить скошенность кривых распределений, а (5) - возможные ошибки при оценке режущих способностей кругов по опытным мерам положения.

\section{Результаты и обсуждение}

В качестве примера на рис. 1 представлены фотофайлы шлифованной поверхности детали

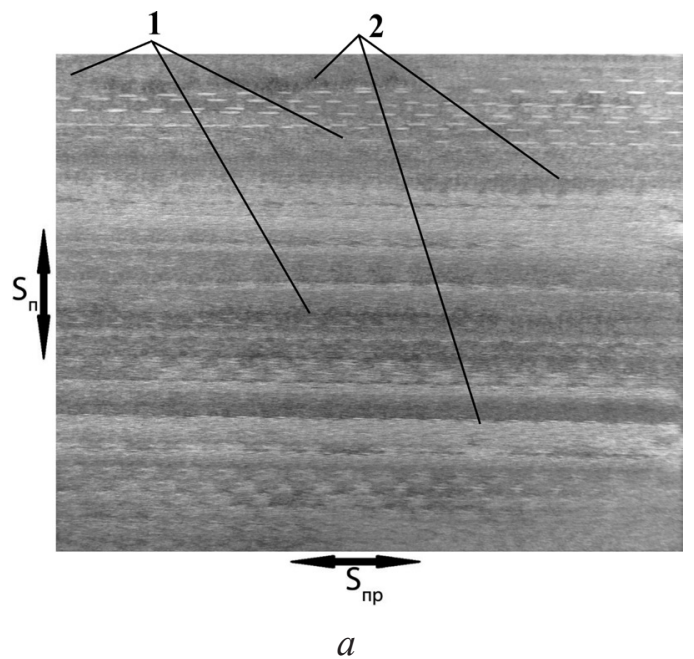

$v=5$ кругом 5A46L10VAX, на которых выделены участки: 1 - без прижогов, 2 - с прижогами.

Результаты обработки фотофайлов данной детали содержатся в табл. 1, в которой зарегистрировано количество пикселей для различных цветов $j=\overline{1 ; 13}$. Из рис. $1, \sigma$ и табл. 1 видно, что количество пикселей прижогов $j=\overline{1 ; 3}$ составляет: $3090960(128,128,0)-$ olive для $j=1$; $2356538(0,128,0)$ - green для $j=2 ; 8131(128$, $0,0)-$ maroon для $j=3$, которые расположены в последовательности снижения плотности прижогов. Аналогичным образом был выполнен поиск прижогов по другим опытам и кругам (см. табл. 4).

В табл. 2 показаны результаты проверки однородности дисперсий с помощью трех критериев: Хартли, Кохрена, Бартлетта; Левене и Брауна-Форсайта. Первая группа из трех статистик в программе представлена общей совокупностью.

Знак «+» в последнем столбце табл. 2 означает, что нуль-гипотеза $\left(H_{0}\right)$ об однородности дисперсий наблюдений принимается по всем критериям, но с учетом возможной ошибки второго рода. Это обусловлено тем, что расчетные уровни значений превышают критические величины незначительно.

Нормальность распределений $\left(H_{0}\right)$ множеств (2) проверена с помощью критерия Шапиро-Уилка $(W)$. Из теоретической статистики известно, что $H_{0}$ подтверждается при удовлетворении неравенств [18]: $p_{i}>0,5, i=\overline{1 ; 4}$. Из табл. 3 и рис. 2 видно, что только при шлифовании кругом из монокристаллического корунда EKE46K3V

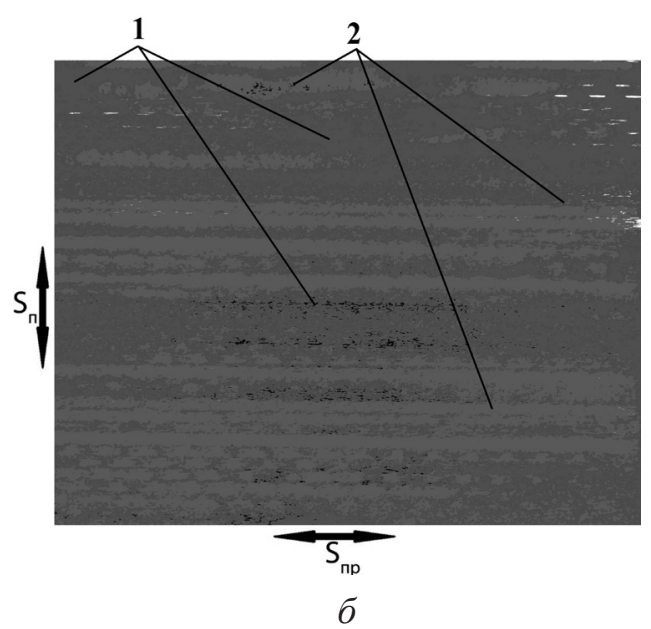

Puc. 1. Фотофайлы шлифованной поверхности детали $v=5$ кругом 5A46L10VAX:

$a$ - исходный фотофайл; $\sigma$ - фотофайл, представленный 16-битным цветным рисунком 
Та блица 1

Частотное распределение встречаемости пикселей каждого цвета

\begin{tabular}{|c|l|l|l|}
\hline Цвет, $j=\overline{1 ; 13}$ & Количество пикселей & \multicolumn{1}{|c|}{$R G B$-код } & \multicolumn{1}{|c|}{$H$ } \\
\hline 1 & 3090960 & $(128,128,0)$ & $\# 808000$ olive \\
\hline 2 & 2356538 & $\mathbf{( 0 , 1 2 8 , 0 )}$ & \#008000 green \\
\hline $\mathbf{3}$ & $\mathbf{8 1 3 1}$ & $\mathbf{( 1 2 8 , 0 , 0 )}$ & \#800000 maroon \\
\hline 4 & 1929496 & $(0,128,128)$ & $\# 008080$ teal \\
\hline 5 & 21581 & $(0,0,0)$ & \#000000 black \\
\hline 6 & 21425 & $(128,128,128)$ & \#808080 fractal \\
\hline 7 & 16948 & $(0,0,128)$ & \#000080 navy \\
\hline 8 & 6037 & $(255,255,255)$ & \#FFFFFF white \\
\hline 9 & 3155 & $(192,192,192)$ & \#C0C0C0 silver \\
\hline 10 & 1789 & $(128,0,128)$ & \#800080 purple \\
\hline 11 & 786 & $(255,255,0)$ & \#FFFF00 yellow \\
\hline 12 & 142 & $(0,0,255)$ & \#0000FF blue \\
\hline 13 & 42 & $(0,255,0)$ & \#00FF00 lime \\
\hline
\end{tabular}

Таблица 2

Проверка однородности дисперсий для прижогов при принятом уровне значимости $\alpha=0,05$

\begin{tabular}{|l|c|c|}
\hline \multicolumn{1}{|c|}{ Критерий } & $\begin{array}{c}\text { Расчетный уровень } \\
\text { значимости } p\end{array}$ & Принятие $H_{0}$ \\
\hline Хартли, Кохрена, Бартлетта & 0,119 & + \\
\hline Левене & 0,177 & + \\
\hline Брауна-Форсайта & 0,221 & + \\
\hline
\end{tabular}

Таблица 3

Проверка нормальности распределений $H_{0}$ по критерию Шапиро-Уилка

\begin{tabular}{|c|c|c|c|}
\hline $\begin{array}{c}\text { Прижоги (1) } \\
\text { по кругам, } i=\overline{1 ; 4}\end{array}$ & $W_{i}$ & $\begin{array}{c}\text { Расчетный уровень } \\
\text { значимости } p_{i}\end{array}$ & Принятие $H_{0 i}$ \\
\hline$\Pi_{1}$ & 0,785 & 0,010 & - \\
\hline$\Pi_{2}$ & 0,928 & 0,432 & - \\
\hline$\Pi_{3}$ & $\mathbf{0 , 9 4 4}$ & $\mathbf{0 , 5 9 5}$ & + \\
\hline$\Pi_{4}$ & 0,910 & 0,284 & - \\
\hline
\end{tabular}

$(i=3)$ наблюдения (2) аппроксимируются кривой нормального распределения с надежностью $p_{3}=0,595$. Наихудшие результаты предсказаны при шлифовании кругом из белого электрокорунда 25AF46L10V5КФ35 $(i=1)$ с уровнем надежности $p_{1}=0,010$. Однако при этом только две детали из десяти (рис. $2, a$ ) имеют прижоги, превышающие среднюю величину $\Pi_{1}=27,34 \%$. Из рис. 2 также видно, что по другим инструментам количество таких деталей возросло: для круга $i=3$ - до пяти, для кругов $i=2 ; 4$ - до четырех по каждому. При этом при шлифовании кругом 5A46L10VAX три детали характеризуются прижогами в пределах 70...90\%.

По наблюдениям микротвердости установлено, что нормальность распределений подтверждена для шлифования кругами $i=1 ; 2 ; 4$, а более строгое требование относительно гомогенности дисперсий нарушено в полном объеме. С учетом полученных результатов интерпретацию (2) по прижогам и микротвердостям ведем с привлечением непараметрического метода. Нормальный 


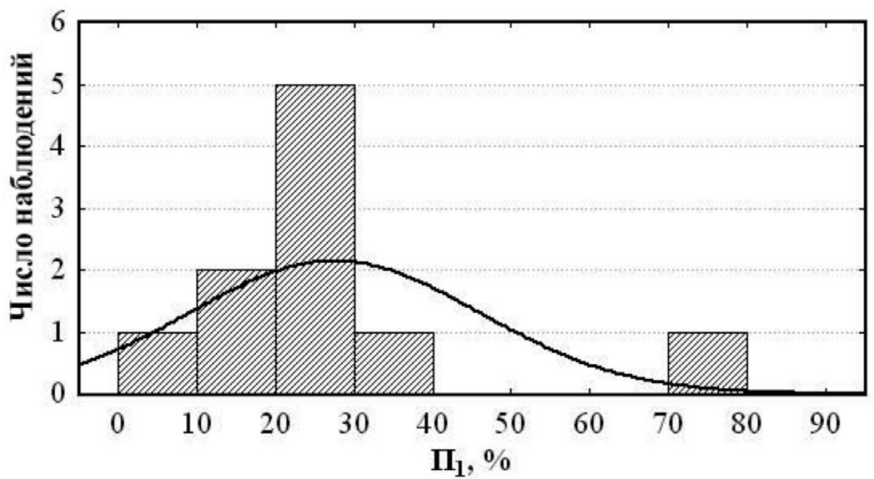

a

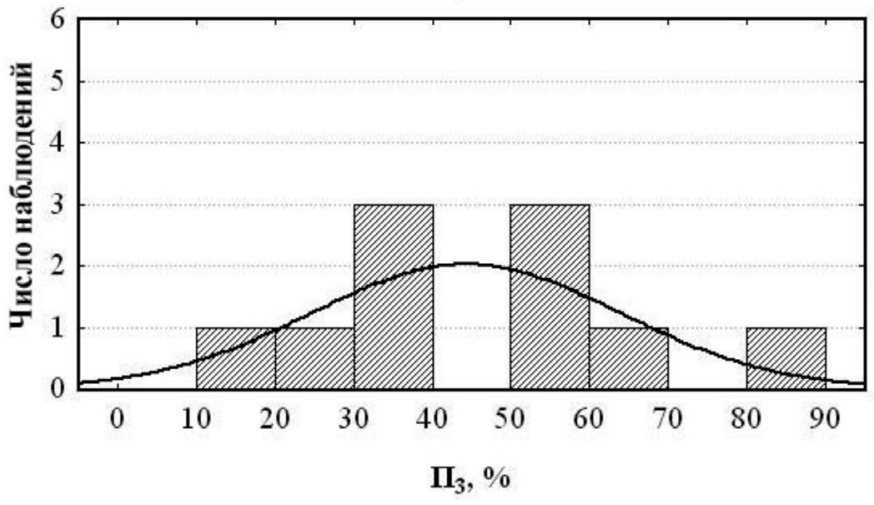

B

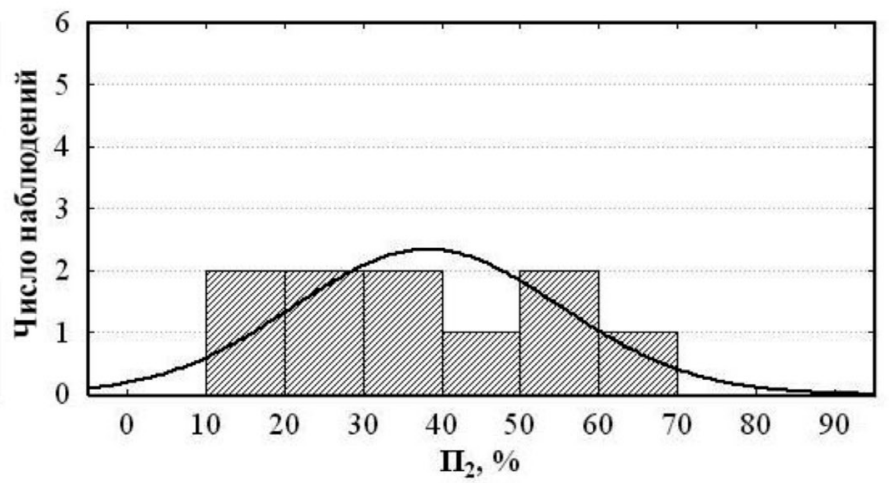

б

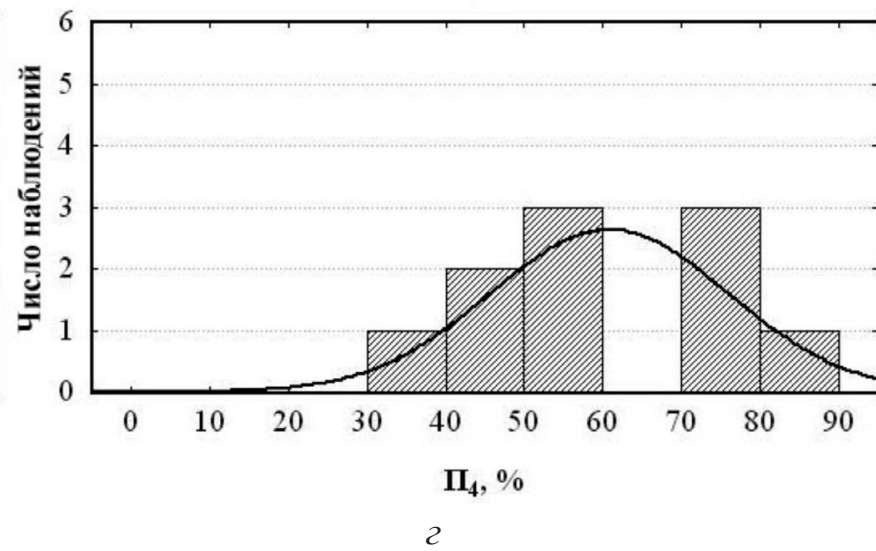

Puc. 2. Гистограммы с наложением кривых нормального распределения для параметра прижогов $\Pi_{i}, i=\overline{1 ; 4}$

аналог статистики приведен в качестве справочного с целью подтверждения его несостоятельности «на чужом поле» [19].

На рис. 3 представлены описательные статистики процентного содержания прижогов на базе параметрического $(a)$ и непараметрического (б) методов статистики при шлифовании кругами $i=\overline{1 ; 4}$. На них «квадратом» выделены меры положения: опытных средних $\bar{\Pi}_{i}(a)$ и медиан $\tilde{\Pi}_{i}(б)$. Остальные обозначения несут различную смысловую нагрузку. На рис. 3, a «прямоугольник» ограничивает рассеяние стандартов ошибки $\pm S D E_{i}$, «усики» - стандартов отклонений $\pm S D_{i}$; на рис. $3, \sigma$ - соответственно квартильные широты $\left|y_{0,75}-y_{0,25}\right|_{i}$, включающие $50 \%$ наблюдений, и размахи $R_{i}=\left|y_{\max }-y_{\min }\right|_{i}$.

По результатам статистического анализа экспериментальных данных выявлено, что при плоском шлифовании деталей ВПК из электрокорунда белого $(i=\overline{1 ; 2})$ по критерию прижогов обладают преимуществами перед инструментами из монокорунда $(i=\overline{3 ; 4})$. При этом $75 \%$ деталей при шлифовании ВПК 25AF46L10V5КФ35 имеют меньшие прижоги, чем 25 \% деталей после шлифования кругами из монокристаллического корунда. Для ВПК $i=2$ сказанное выражено в меньшей мере и касается только круга $5 \mathrm{~A}(i=4)$. Достоинства ВПК перед кругами из монокристаллического корунда обусловлены следующими закономерностями. Во-первых, радиусы округления зерен электрокорунда белого меньше, чем у зерен монокорунда. Они содержат большее количество острых вершин: $20 \%$ - для 25А, $11 \%$ для зерен монокорунда [24]. В то же время зерна 25А имеют твердость по Моссу 9,03, а монокристаллического корунда -9 . Все это позволяет им легче внедряться в металл, снижает температуру шлифования и прижоги на поверхности деталей. Во-вторых, круги $i=\overline{1 ; 2}$ характеризуются высокопористой структурой, а инструменты из монокорунда - средней и открытой структурами. Сказанное при работе ВПК дополнительно приводит к снижению температуры резания и прижогов [25]. В-третьих, в каждой из групп: ВПК $i=1 ; 2$ и кругов из монокорунда $i=3 ; 4$ - инструменты $i-2$ и 4 имеют твердость на одну степень выше по сравнению с кругами $i-1$ и 3 . По результатам эксперимента сниже- 


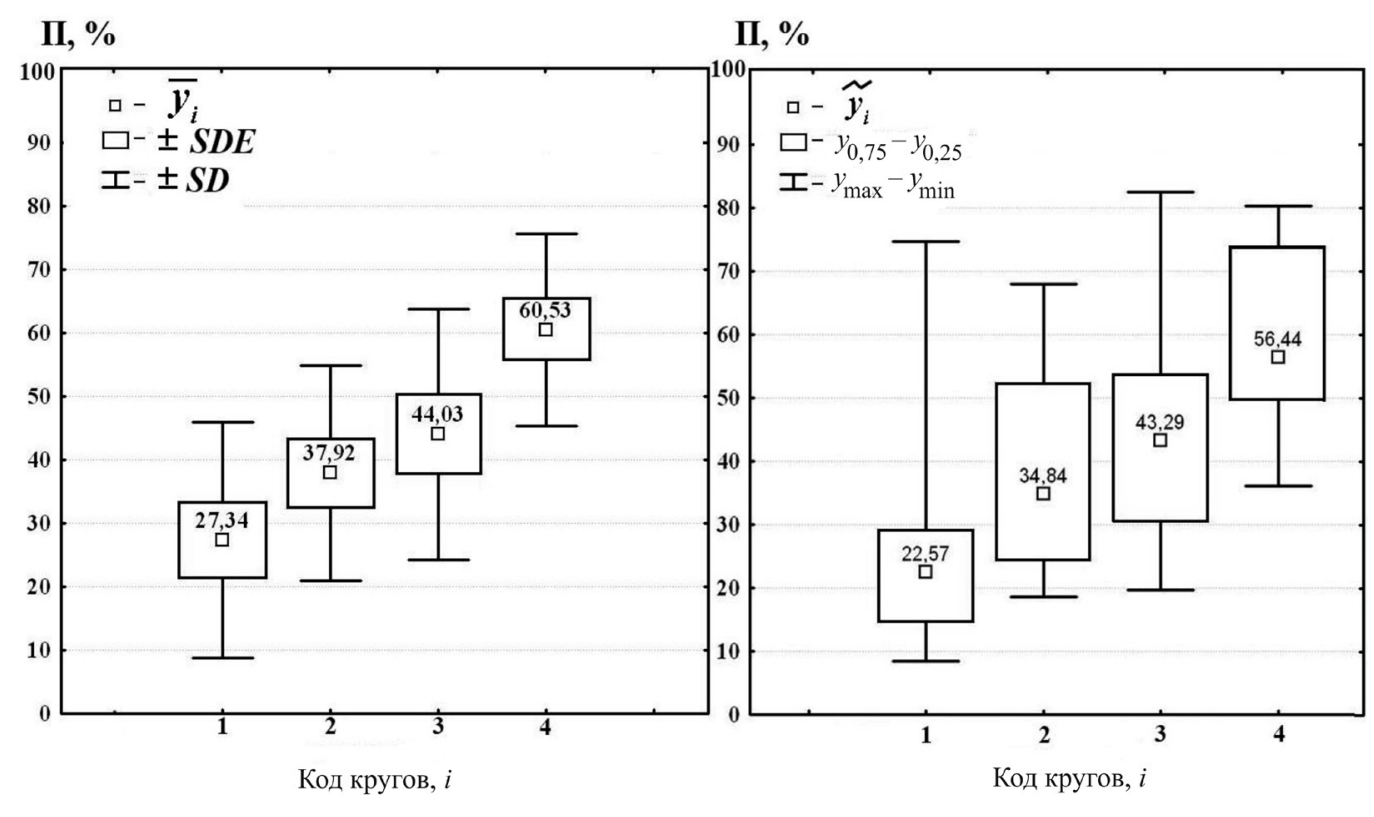

$a$

$\sigma$

Puc. 3. Описательные параметрические (a) и непараметрические (б) для параметров $\Pi_{i}, i=\overline{1 ; 4}$

ние твердости кругов даже в пределах каждой группы сопровождается уменьшением прижогов. Сказанное объясняется тем, что мостики связки, скрепляющие отдельные зерна, при резании упруго деформируются. У мягких кругов данный процесс протекает в большей степени, чем у твердых, содержащих повышенное количество связки. Это позволяет выступающим зернам в мягких кругах во время работы частично вдавливаться в его «черепок». Тогда припуск снимается большим количеством равновыступающих абразивных зерен при меньшей толщине среза, в силу чего уменьшается интенсивность тепловых импульсов и температур в зоне шлифования [7]. Из рис. 3, $а$ видно, что наименьшие стандарты ошибки имеются при шлифовании прессованными кругами из монокорунда.

Рис. 4 иллюстрирует, что наибольшие величины опытных медиан микротвердостей соответствуют наименьшим прижогам деталей (см. рис. 3, б). Сказанное позволяет утверждать, что тепловой источник при шлифовании вызвал разупрочнение поверхностей (прижоги вторичного отпуска) закаленных деталей $40 X$ без вторичной закалки $[3,12,13]$. Полученные результаты позволяют констатировать, что предложенный метод количественной оценки прижогов с использованием цифровых технологий по мерам положения показал высокую адекватность и мо- жет использоваться как в научных целях, так и в производственных условиях.

В табл. 4 представлены опытные и ожидаемые меры положения для прижогов и микротвердостей деталей, прошлифованных исследуемыми кругами. По опытным коэффициентам $\mathrm{K}_{\mathrm{мi}}$ (3) выявлено, что кривые формы распределений для обоих выходных параметров процесса чаще характеризуются положительной асимметрией, так как в шести из восьми случаев они предсказаны меньше единицы. Наименьшая опытная медиана по прижогам и наибольшая по микротвердости получены при шлифовании ВПК 25AF46L10V5КФ35 $(i=1)-\tilde{\Pi}_{1}=22,57 \%$, $\tilde{H} V_{1}=3910,70 \mathrm{MПа,} \mathrm{что} \mathrm{позволяет} \mathrm{рекомен-}$ довать его для шлифования закаленных деталей. Соответственно наихудшие результаты по состоянию поверхности имеются при работе кругом 5A46L10VAX $(i=4)$. В общем случае следует констатировать, что для кругов $i=\overline{2 ; 4}$ опытные медианы $\tilde{\Pi}_{i}$ монотонно возрастают по сравнению с базовым $i=1$ : в 1,54 раза для ВПК 25AF46M12V5ПО3 $(i=2)$; в 1,92 раза - для круга EKE46K3V ( $i=3)$ и в 2,5 раза - для круга 5A46L10VAX $(i=4)$. По опытным медианам микротвердостей перечисленные круги образуют соответственно убывающую последовательность от 3910,7 до 3167,48 МПа. По прогнозируемым мерам положения отмеченные тенденции выглядят менее убедительно, поскольку неко- 


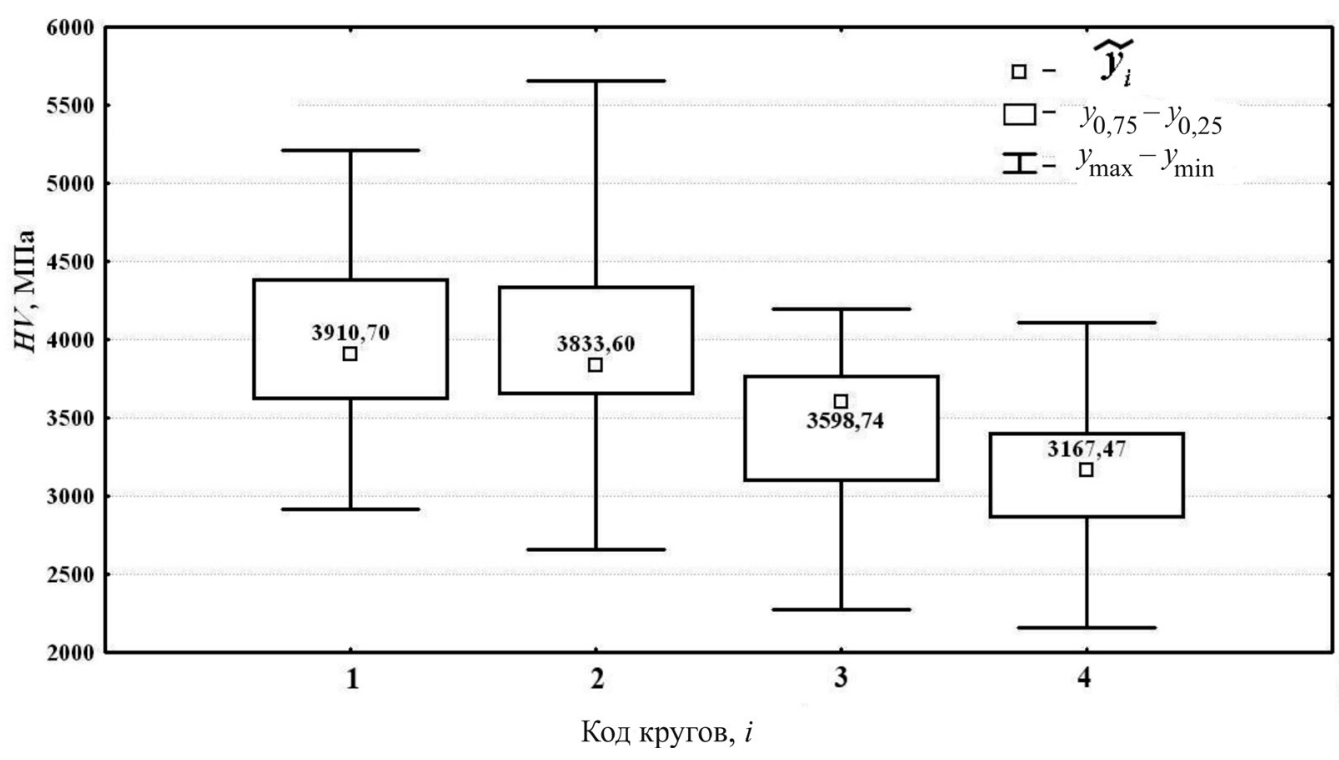

Puc. 4. Описательные непараметрические статистики для микротвердости шлифованных поверхностей

Т а бли ца 4

Влияние кругов на меры положения и коэффициенты (3)-(6)

\begin{tabular}{|c|c|c|c|c|c|c|c|c|c|}
\hline $\begin{array}{l}\text { Пара- } \\
\text { метр }\end{array}$ & $\begin{array}{c}\text { Круги } \\
i\end{array}$ & $y_{i}$ • & $\tilde{y}_{i}$ & $y_{i}$. & $m \hat{y}_{i}$ & $\mathrm{~K}_{\mathrm{M} i}(3)$ & $\widehat{\mathrm{K}}_{\mathrm{M} i}(4)$ & $\mathrm{K}_{i}(5)$ & $\widehat{\mathrm{K}}_{i}(6)$ \\
\hline \multirow{4}{*}{$\Pi_{i}, \%$} & 1 & 27,34 & 22,57 & 35,79 & 33,57 & 0,83 & 0,94 & 1,00 & 1,00 \\
\hline & 2 & 37,92 & 34,84 & 37,43 & 39,29 & 0,92 & 1,05 & 1,54 & 1,17 \\
\hline & 3 & 44,03 & 43,29 & 40,20 & 39,29 & 0,98 & 0,98 & 1,92 & 1,17 \\
\hline & 4 & 60,53 & 56,44 & 55,61 & 44,86 & 0,93 & 0,81 & 2,50 & 1,34 \\
\hline \multirow{4}{*}{$\begin{array}{l}H V_{i}, \\
\text { МПа }\end{array}$} & 1 & 3939,90 & 3910,70 & 3965,92 & 3872,15 & 0,99 & 0,98 & 1,00 & 1,00 \\
\hline & 2 & 3991,93 & 3833,60 & 3965,92 & 3872,15 & 0,96 & 0,98 & 0,98 & 1,00 \\
\hline & 3 & 3467,56 & 3598,74 & 3390,60 & 3383,11 & 1,04 & 1,00 & 0,92 & 0,87 \\
\hline & 4 & 3159,75 & 3167,48 & 3236,70 & 3383,11 & 1,00 & 1,05 & 0,81 & 0,87 \\
\hline
\end{tabular}

Примечание. Круги $i$ : 1 - 25AF46L10V5КФ35; 2 - 25AF46M12V5ПO3; 3 - EKE46K3V; 4 - 5A46L10VAX.

торые из ожидаемых опорных значений представлены общими величинами. Равноценные режущие свойства кругов по ожидаемым мерам положения $\Pi_{i}$ и $H V_{i}, i=\overline{1 ; 4}$ оцениваются общими величинами. Как видно из табл. 4 , они зависят от выходного параметра процесса. По прижогам к ним относятся круги $i=2 ; 3\left(\Pi_{i}=39,29 \%\right)$, а по микротвердостям - ВПК $i=1 ; 2$ и круги из монокорунда $i=3 ; 4$, представленные двумя ожидаемыми медианами: $H V_{i}=3872,15 \mathrm{MПа,} i=\overline{1 ; 2}$ и $H V_{i}=3383,11 \mathrm{MПа,} i=\overline{3 ; 4}$. Различие между коэффициентами (5) и (6) свидетельствует о целесообразности проведения второго этапа ОДА. Так, при шлифовании кругом $i=4$ получены коэффициенты по прижогам: 2,5 по (5) и 1,34 - по (6). Соответственно по микротвердостям имеем коэффициенты, равные 0,81 и 0,87 .
В табл. 5 представлены результаты оценки стабильности образования прижогов и формирования микротвердости. По результатам ОДА и множественного анализа (2) предпочтение отдано квартильным широтам и полученным на их базе коэффициентам $\mathrm{K}_{\text {стіз }}, i=\overline{1 ; 4}$. Выявлено, что наилучшая стабильность процесса по прижогам предсказана при шлифовании ВПК 25AF46L10V5КФ35 $(i=1)-\mathrm{KШ}_{1}=16,33 \%$, наихудшая - для ВПК 25AF46M12V5ПО3 $(i=2)-\mathrm{KШ}_{2}=30,70 \%$. Круги $i=4$ и $i=3$ последовательно занимают второе и третье место. Параметрический метод «на чужом поле» показал, что по стандартам отклонений и размахам наибольшая прецизионность процесса обеспечена при шлифовании кругом 5A46L10VAX $(i=4)$ с коэффициентами стабильности $\mathrm{K}_{\text {ст41 }}=1,23$ и 
Таблица 5

Оценка режущих способностей кругов по мерам рассеяния и коэффициентам стабильности (7)-(9)

\begin{tabular}{|c|c|c|c|c|c|c|c|}
\hline \multirow{2}{*}{ Параметр } & \multirow{2}{*}{ Круги $i$} & \multirow{2}{*}{$S D_{i}$} & \multirow{2}{*}{$R_{i}$} & \multirow{2}{*}{ КШ $_{i}$} & \multicolumn{3}{|c|}{$\mathrm{K}_{\text {стіе }}$} \\
\hline & & & & & $e=1(7)$ & $e=2(8)$ & $e=3(9)$ \\
\hline \multirow{4}{*}{$\Pi_{i}, \%$} & 1 & 18,58 & 66,36 & 16,33 & 1,00 & 1,00 & 1,00 \\
\hline & 2 & 17,02 & 49,29 & 30,70 & 1,09 & 1,35 & 0,53 \\
\hline & 3 & 19,73 & 62,91 & 27,73 & 0,94 & 1,06 & 0,59 \\
\hline & 4 & 15,14 & 44,20 & 25,46 & 1,23 & 1,50 & 0,64 \\
\hline \multirow{4}{*}{$H V_{i}$, МПа } & 1 & 527,36 & 2301,45 & 766,28 & 1,00 & 1,00 & 1,00 \\
\hline & 2 & 678,02 & 2997,95 & 741,87 & 0,78 & 0,77 & 1,03 \\
\hline & 3 & 443,95 & 1921,50 & 670,70 & 1,19 & 1,20 & 1,14 \\
\hline & 4 & 459,96 & 1951,75 & 553,59 & 1,15 & 1,18 & 1,38 \\
\hline
\end{tabular}

Примечание. Круги $i$ : 1 - 25AF46L10V5КФ35; 2 - 25AF46M12V5ПO3; 3 - EKE46K3V; 4 - 5A46L10VAX.

$\mathrm{K}_{\text {ст42 }}=1,5$. По другим инструментам оценки по (7) и (8) разнятся: по стандартам отклонений наименьшую прецизионность процесса имеет круг $i=3$, а по размахам - ВПК $i=1$. Сказанное относительно стабильности процесса по прижогам наглядно иллюстрирует рис. 3. По мерам рассеяния микротвердости оценки (7)-(9) в области наибольшей воспроизводимости процесса различаются между собой в меньшей мере, чем по прижогам: первую позицию по КШ занимает круг $i=4$ с $_{\text {ст43 }}=1,38$, а по $S D_{i}$ и $R_{i}-$ круг $i=3$ :

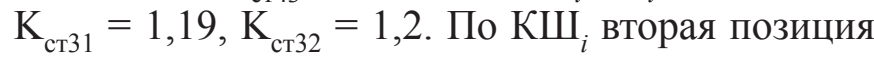
отдана инструменту EKE46K3V, а по параметрическим мерам рассеяния - кругу 5A46L10VAX. При этом коэффициенты стабильности процесса по (7) и (8) для кругов $i=3 ; 4$ разнятся незначительно: для первого места $\mathrm{K}_{\text {стзе }}=1,19-1,2$, а для второго $\mathrm{K}_{\text {ст4e }}=1,15-1,18, e=\overline{1 ; 2}$, поэтому круги из монокорунда по стабильности микротвердости могут быть признаны равноценными. Третья позиция по (9) отдана ВПК $i=2$, а четвертая базовому кругу, хотя стабильность их работы практически совпадает. Параметрический метод статистики третье место предсказал для ВПК $i=1$, за ним с большим отрывом находится ВПК $i=2$. Следовательно, «на чужом поле» результаты стабильности процесса для параметрического метода оказались неточными и менее надежными, чем по КШ ${ }_{i}$. Сказанное по КШ ${ }_{i}$ и $R_{i}$ отражено на рис. 4.

Считаем, что точность измерений микротвердости выше по сравнению с прижогами. При этом дополнительно увеличен объем выборки с 10 до 30 опытов. В связи с изложенным окончательные выводы по стабильности работы кругов целесообразно вести по КШ микротвердости. По результатам данного эксперимента метод поиска процентного содержания прижогов следует использовать для оценки мер положения и выявления физических явлений шлифования, протекающих в зоне резания.

\section{Выводы}

1. Разработанная методика количественного контроля прижогов с использованием цифровых технологий включает в себя три этапа: макросъемку исходной поверхности в отраженных лучах света; ее оцифровку в программе Adobe Photoshop CS6 13.1.2 и конвертирование в виде растровых изображений цветов с возможными оттенками не более 16. Ее положительными качествами являются: низкая трудоемкость, экологическая безопасность, возможность широкого использования в любых производственных условиях и, в конечном итоге, возможность количественной оценки интенсивности прижогов. Она апробирована при плоском шлифовании закаленных деталей из стали 40Х и показала хорошую сходимость с результатами по микротвердости поверхности.

2. Возрастание прижогов, сопровождаемое снижением микротвердости поверхности, свидетельствует о том, что при шлифовании деталей доминирует тепловое разупрочнение поверхности без вторичной закалки.

3. Подтверждено, что для улучшения условий бесприжогового шлифования закаленных деталей целесообразно снижать степень твердости кругов. 
4. Окончательные рекомендации по выбору кругов должны учитывать конструктивные особенности деталей и условия шлифования, поскольку оптимальные характеристики кругов по мерам положения и рассеяния различаются: по опорным величинам следует вести шлифование ВПК 25AF46L10V5КФ35, а по прецизионности процесса - кругами 5A46L10VAX и EKE46K3V.

5. Коэффициенты (4), (6)-(9) целесообразно использовать для уточнения моделей множественного дисперсионного анализа, применяемых при многокритериальном управлении процессом шлифования.

\section{Список литературы}

1. Рудометов Ю.И. Применение абразивных инструментов, пропитанных суспензиями импрегнаторов // СТИН. - 2012. - № 11. - С. 34-37.

2. Маслов Е.Н. Теория шлифования материалов. М.: Машиностроение, 1974. - 320 с.

3. Лебедев В.Г., Клименко Н.Н., Аль-Аджейлат С.А. Механизм образования прижогов при шлифовании деталей из закаленных сталей // Наукові нотатки: міжвузівський збірник. - Луцьк, 2013. - Вып. 40. C. 141-143.

4. Аль-Аджейлат С.А., Лебедев В.Г. Формирование прижогов отпуска при шлифовании направляющих тяжелых прессов кругами из КНБ // Проблеми техніки. - 2007. - № 4. - С. 128-150.

5. Аль-Аджейлат С.А., Лебедев В.Г. Энергетические условия образования прижогов закалки при шлифовании направляющих тяжелых прессов кругами КНБ // Проблеми техніки. - 2008. - № 1. C. $130-152$.

6. Инженерия поверхности деталей / А.Г. Суслов, В.Ф. Безъязычный, Ю.В. Панфилов, С.Г. Бишутин, И.В. Говоров, А.О. Горленко, Д.И. Петрешин, В.И. Сакало, С.Ю. Съянов, В.П. Тихомиров, О.Н. Федонин, В.П. Федоров, Д.Н. Финатов, А.Н. Щербаков; под ред. А.Г. Суслова. - М.: Машиностроение, 2008. -318 c.

7. Эльянов В.Д., Куликов В.Н. Прижоги при шлифовании. - М.: НИИмаш, 1974. - 64 с.

8. ANSI/AGMA 2007-B92. Surface temper etch inspection after grinding. - [S. 1.]: [S. n.], 1992. -14 p.

9. Способ выявления прижогов на металлах, например на титане и его сплавах, и вещество для его осуществления: патент 2044302 Российская Федерация: МПК ${ }^{8}$ G 01 N 021/64 / М.Н. Медведев, Е.Н. Мельникова; патентообладатель Московский вечерний металлургический институт. - № 92015489/25; заявл. 30.12.1992; опубл. 20.09.1995.
10. Неразрушающий способ экспрессного выявления зон на поверхности металлических деталей со шлифовочными или эксплуатационными прижогами: патент 2407996 Российская Федерация: МПК G 01 L1/100 / Э.А. Кочаров, В.С. Олешко; заявитель и патентообладатель Э.А. Кочаров. - № 2008129897/28; заявл. 22.07.2010; опубл. 27.12.2010, Бюл. № 36. - 9 с.

11. Геллер Ю.А. Инструментальные стали. 5-е изд. - М.: Металлургия, 1983. - 527 с.

12. Суоминен Л. Обнаружение дефектов шлифования деталей из ферромагнитных материалов с использованием эффекта Баркгаузена // В мире неразрушающего контроля. - 2011. - № 2 (52). - С. 74-78.

13. Grinding process control using the magnetic Barkhausen noise method / B.A. Shaw, J.T. Evans, A.S. Wojtas, L. Suominen // Electromagnetic nondestructive evaluation (II): proceedings of the 3rd International Workshop on E'NDE, Reggio Calabria, Italy, September 1997. - Amsterdam: IOS Press, 1998. - P. 82-91.

14. Пальцеева Ю.А., Бабошкин А.Ф. Методика получения трехмерной модели шероховатой поверхности // Инструмент и технологии. - 2006. - Вып. 1, № 23. - С. 135-140.

15. Справочник по конструкционным материалам / Б.Н. Арзамасов, Т.В. Соловьева, С.А. Герасимов и др. - М.: Изд-во МГТУ, 2006. -640 с.

16. Солер Я.И., Казимиров Д.Ю. Подходы к оценке опорной части поверхности шлифованных плоскостей титановых деталей абразивными кругами Norton // Фундаментальные и прикладные проблемы техники и технологии. - 2014. - № 5 (307). C. $142-150$.

17. Солер Я.И., Лгалов В.В. Изучение микротвердости формообразующих деталей штамповой оснастки при абразивном шлифовании // Вестник ИрГТУ. - 2012. - № 7 (66). - С. 48-54.

18. Закс Л. Статистическое оценивание / пер. с нем. В. Н. Варыгина; науч. ред. и предисл. Ю.П. Адлера, В.Г. Горского. - М.: Статистика, 1976. - 598 с.

19. Холлендер М., Вулф Д. Непараметрические методы статистики / пер. с англ. Д.С. Шмерлинга; науч. ред. Ю.П. Адлера, Ю.Н. Тюрина. - М.: Финансы и статистика, 1983. - 518 с.

20. ГОСТ Р ИСО 5725-2-2002. Точность (правильность и прецизионность) методов и результатов измерений. Ч. 2. Основной метод определения повторяемости воспроизводимости стандартного метода измерений. - Введен 2002-01-11. - М.: Изд-во стандартов, 2002. - $58 \mathrm{c}$.

21. Солер Я.И., Нгуен В.Л., Гуиол И.А. Прогнозирование микрогеометрии при маятниковом шлифовании плоских деталей из стали 13Х15H4AМ3 высокопористыми инструментами // Обработка металлов 
(технология, оборудование, инструменты). - 2014. № 2 (63). - С. 21-30.

22. Солер Я.И., Нгуен В.Л., Гуцุол И.А. Статистические подходы к микрорельефу плоских деталей из закаленной стали 08X15Н5Д2Т при маятниковом шлифовании высокопористыми кругами из кубического нитрида бора и синтеркорунда // Вестник ИрГТУ. - 2014. - № 4 (87). - C. 33-40.

23. Soler Ya.I., Kazimirov D.Yu., Prokop'eva A.V. Optimizing the grinding of high-speed steel by wheels of cubic boron nitride // Russian Engineering Research. 2007. - Vol. 27, iss. 12. - P. 916-919. - doi: 10.3103/ $\mathrm{S} 1068798 \mathrm{X} 07120180$.

24. Носенко В.А., Носенко С.В. Технология шлифования металлов: монография. - Старый Оскол: ТНТ, 2013. - 616 с. - (Тонкие наукоемкие технологии).

25. Старков В.К. Шлифование высокопористыми кругами. - М.: Машиностроение, 2007. - 688 с.

\title{
OBRABOTKA METALLOV
}

(METAL WORKING AND MATERIAL SCIENCE)

N 1(66), January - March 2015, Pages 6-19

\section{Quantitative assessment of burns while flat grinding hardened parts made of steel 37Cr4 by abrasive wheels of different porosity}

Soler Ya. I., Ph.D. (Engineering), Associate Professor, e-mail: solera@istu.irk.ru

Kazimirov D. Yu., Ph.D. (Engineering), Associate Professor, e-mail: kazimirov@fromru.com

Nguyen V. L., Ph.D. student, e-mail: nhatle007@gmail.com

National Research Irkutsk State Technical University, 83, Lermontov st., Irkutsk, 664074, Russian Federation

\begin{abstract}
A method for quantitative assessment of grinding burns is developed on the basis of digital technology. It is tested in conditions of pendulum grinding of hardened parts made of steel $37 \mathrm{Khr} 4$ by abrasive wheels of different porosity: 25AF46L10V5KF35 $(i=1), 25 \mathrm{AF} 46 \mathrm{M} 12 \mathrm{~V} 5 \mathrm{PO} 3(i=2)$, EKE46K3V $(i=3), 5 \mathrm{~A} 46 \mathrm{~L} 10 \mathrm{VAX}(i=4)$. Abrasive wheels with $i=1 ; 2$ relate to high-porous wheels, while the abrasive wheels with $i=3 ; 4$ are made of monocrystal carborundum and have standard porosity (producer - company Dorfner schleifmittelwerk (Germany)). To confirm the reliability of the proposed methodology for assessing burn marks a study of details microhardness is undertaken. In consideration of grinding stochastic character, statistical methods (particularly - rank): parametric and nonparametric are used to reduce the observations. They give opportunity to evaluate the reliability of decisions as well as the cuttability of wheels not only by the measures of position but by measures of dispersion. The second characteristic of the marginal frequency distribution is more important while grinding of critical parts on adapted machines with manual control for eliminating rejected probability. The statistical results have shown that in the infringements of homoscedasticity and normality of observations' allocation, the parametric method reduced to dislodgement of measures of position and confidence intervals. A correlation between measures of position for percent burn content and microhardness is established. Tool 25AF46L10V5KF35 grinding with regime: $\mathrm{v}_{\mathrm{c}}=35 \mathrm{~m} \cdot \mathrm{s}^{-1}, \mathrm{~s}_{1}=7 \mathrm{~m} \cdot \mathrm{min}^{-1}, \mathrm{~s}_{\mathrm{c}}=1 \mathrm{~mm} .(\mathrm{d} . \mathrm{s} .)^{-1}, t=0,015$ $\mathrm{mm}, \mathrm{z}=0,15 \mathrm{~mm}$ secures the greatest microhardness of parts made of steel $37 \mathrm{Khr} 4$ in the minimum burns. This investigation has shown that grinding parts by wheels $<<$ Eqn 068 .wmf $>>$ runs in the softening of their surfaces, but no re-hardening burn. The wheel $i=2$ with pore-forming ПО 3 is probably used for decrease of rejected parts.
\end{abstract}

\section{Keywords:}

grinding, burns, assessment, microhardness, statistic, mean, median, measure of position, digital technology

DOI: 10.17212/1994-6309-2015-1-6-19

\section{References}

1. Rudometov Yu.I. Primenenie abrazivnykh instrumentov, propitannykh suspenziyami impregnatorov [Abrasive tools steeped in special suspensions]. STIN - Russian Engineering Research, 2012, no. 11, pp. 34-37. (In Russian)

2. Maslov E.N. Teoriya shlifovaniya materialov [Theory of materials grinding]. Moscow, Mashinostroenie Publ., 1974. $320 \mathrm{p}$. 
3. Lebedev V.G., Klimenko N.N., Al'-Adzheilat S.A. [The mechanism of formation of burns in the grinding of hardened steel parts]. Mizhvuzivs'kyj zbirnyk "Naukovi notatky" [Interuniversity collection "Scientific Notes"], 2013, iss. 40, pp. 141-143.

4. Al'-Adzheilat S.A., Lebedev V.G. Formirovanie prizhogov otpuska pri shlifovanii napravlyayushchikh tyazhelykh pressov krugami iz KNB [Formation burn marks when grinding rails heavy presses by abrasive wheels CBN]. Problemy tehniky - Scientific and Industrial Journal, 2007, no. 4, pp. 128-150.

5. Al'-Adzheilat S.A., Lebedev V.G. Energeticheskie usloviya obrazovaniya prizhogov zakalki pri shlifovanii napravlyayushchikh tyazhelykh pressov krugami KNB [Energy conditions for the formation of burn marks hardening when grinding rails heavy presses by abrasive wheels CBN]. Problemy tehniky - Problems Technology, 2008, no. 1, pp. 130-152.

6. Suslov A.G., Bez”yazychnyi V.F., Panfilov Yu.V., Bishutin S.G., Govorov I.V., Gorlenko A.O., Petreshin D.I., Sakalo V.I., S"yanov S.Yu., Tikhomirov V.P., Fedonin O.N., Fedorov V.P., Finatov D.N., Shcherbakov A.N. Inzheneriya poverkhnosti detalei [Surface engineering details]. Moscow, Mashinostroenie Publ., 2008. 318 p.

7. El'yanov V.D., Kulikov V.N. Prizhogi pri shlifovanii [Grinding burn marks]. Moscow, NIImash Publ., 1974. $64 \mathrm{p}$.

8. ANSI/AGMA 2007-B92. Surface temper etch inspection after grinding, 1992. $14 \mathrm{p}$.

9. Medvedev M.N., Mel'nikova E.N. Sposob vyyavleniya prizhogov na metallakh, naprimer na titane i ego splavakh, $i$ veshchestvo dlya ego osushchestvleniya [A method of detecting burn marks on metals, such as titanium and its alloys, and a substance for its realization]. Patent RF, no. 2044302, 1995.

10. Kocharov E.A., Oleshko V.S. Nerazrushayushchii sposob ekspressnogo vyyavleniya zon na poverkhnosti metallicheskikh detalei so shlifovochnymi ili ekspluatatsionnymi prizhogami [Non-destructive method of express identify areas on the surface of metal parts with grinding or operating burn marks]. Patent RF, no. 2407996, 2010.

11. Geller Yu.A. Instrumental'nye stali [Tool steels]. 5th ed. Moscow, Metallurgiya Publ., 1983. 527 p.

12. Suominen L. Obnaruzhenie defektov shlifovaniya detalei iz ferro-magnitnykh materialov s ispol'zovaniem effekta Barkgauzena [Detecting grinding damage in gears with the barkhausen noise]. V mire nerazrushayushchego kontrolya - In the world of non-destructive testing, 2011, no. 2 (52), pp. 74-78.

13. Shaw B.A., Evans J.T., Wojtas A.S., Suominen L. Grinding process control using the magnetic Barkhausen noise method. Electromagnetic nondestructive evaluation (II). Proceedings of the 3rd International Workshop on E’NDE, Reggio Calabria, Italy, September 1997, Amsterdam, IOS Press, 1998, pp. 82-91.

14. Pal'tseva Yu.A., Baboshkin A.F. Metodika polucheniya trekhmernoi modeli sherokhovatoi poverkhnosti [Technique to obtain 3D model of a rough surface]. Instrument $i$ tekhnologii - Tools and Technology, 2006, no. 23, iss. 1 , pp. $135-140$.

15. Arzamasov B.N., Solov'eva T.V., Gerasimov S.A. et al. Spravochnik po konstruktsionnym materialam [Handbook of structural materials]. Moscow, Bauman MSTU Publ., 2006. 640 p.

16. Soler Ya.I., Kazimirov D.Yu. Podkhody k otsenke opornoi chasti poverkhnosti shlifovannykh ploskostei titanovykh detalei abrazivnymi krugami Norton [Principles for the estimation of a bearing area of polished planes of titanium parts by abrasive wheels Norton]. Fundamental'nye i prikladnye problemy tekhniki $i$ tekhnologii Fundamental and Applied Problems of Engineering and Technology, 2014, no. 5 (307), pp. 142-150.

17. Soler Ya.I., Lgalov V.V. Izuchenie mikrotverdosti formoobrazuyushchikh detalei shtampovoi osnastki pri abrazivnom shlifovanii [Study of shaping die tooling parts microhardness under abrasive grinding]. Vestnik Irkutskogo gosudarstvennogo tekhnicheskogo universiteta - Bulletin of Irkutsk State Technical University, 2012, no. 7 (66), pp. 48-54.

18. Sachs L. Statistische Auswertungsmethoden. Berlin, New York, Springer-Verlag, Heidelberg, 1972. 548 p. (Russ. ed.: Zaks L. Statisticheskoe otsenivanie. Trans. eng. Varygina V.N. Edited by Adler Yu.P., Gorskii V.G. Moscow, Statistika Publ., 1976. 598 p.).

19. Hollander M., Wolfe D.A. Nonparametric Statistical Methods. New York, John Wiley \& Sons, 1973. 528 p. (Russ. ed.: Khollender M., Vulf D. Neparametricheskie metody statistiki. Trans. eng. Shmerling D.S. Edited by Adler Yu.P., Tiurin Yu.N. Moscow, Finansy i statistika Publ., 1983. 518 p.).

20. GOST R ISO 5725-2-2002. Tochnost' (pravil'nost' i pretsizionnost') metodov i rezul 'tatov izmerenii. Ch. 2. Osnovnoi metod opredeleniya povtoryaemosti vosproizvodimosti standartnogo metoda izmerenii [Accuracy (trueness and precision) of measurement methods and results. Pt. 2. Basic method for the determination of repeatability and reproducibility of a standard measurement method]. Moscow, Standartinform Publ., 2002. 58 p.

21. Soler Ya.I., Nguyen V.L., Gutsol I.A. Prognozirovanie mikrogeometrii pri mayatnikovom shlifovanii ploskikh detalei iz stali 13Kh15N4AM3 vysokoporistymi instrumentami [Prediction of microgeometry in pendulous 
grinding of plane parts made of steel 13X15H4AM3 by high porous wheels]. Obrabotka metallov (tekhnologiya, oborudovanie, instrumenty) - Metal Working and Material Science, 2014, no. 2 (63), pp. 21-30.

22. Soler Ya.I., Nguyen V.L., Gutsol I.A. Statisticheskie podkhodyk mikrorel'efu ploskikh detalei iz zakalennoi stali 08Kh15N5D2T pri mayatnikovom shlifovanii vysokoporistymi krugami iz kubicheskogo nitrida bora i sinterkorunda [Statistical approaches to microrelief of flat parts made of hardened steel 08Х15НД2Т under pendulous grinding by high porous wheels made from cubic boron nitride and synthesis corundum]. Vestnik Irkutskogo gosudarstvennogo tekhnicheskogo universiteta - Bulletin of Irkutsk State Technical University, 2014, no. 4 (87), pp. 33-40.

23. Soler Ya.I., Kazimirov D.Yu., Prokop'eva A.V. Optimizing the grinding of high-speed steel by wheels of cubic boron nitride. Russian Engineering Research, 2007, vol. 27, iss. 12, pp. 916-919. doi: 10.3103/S1068798X07120180

24. Nosenko V.A., Nosenko S.V. Tekhnologiya shlifovaniya metallov: monografiya [Metal grinding technology]. Stary Oskol, TNT Publ., 2013. 616 p.

25. Starkov V.K. Shlifovanie vysokoporistymi krugami [Highly porous grinding wheels]. Moscow, Mashinostroenie Publ., 2007. 688 p.

Received 20 January 2015

Revised 10 February 2015

Accepted 15 February 2015 